\title{
Early-life exposure to endocrine-disrupting chemicals and pubertal development in girls
}

\author{
Jeong Eun Lee, $\mathrm{MD}^{1}$, \\ Hae Woon Jung, $\mathrm{MD}^{2}$, \\ Yun Jeong Lee, $\mathrm{MD}^{3}$, \\ Young Ah Lee, MD, PhD ${ }^{3}$
}

'Department of Pediatrics, Inje University Busan Paik Hospital, Busan, Korea

${ }^{2}$ Department of Pediatrics, Kyung Hee University Medical Center, Seoul, Korea ${ }^{3}$ Department of Pediatrics, Seoul National University Children's Hospital, Seoul, Korea
Received: 15 May, 2019

Revised: 17 June, 2019

Accepted: 18 June, 2019

\section{Address for correspondence:}

Young Ah Lee, MD, PhD

Department of Pediatrics, Seoul National University Children's Hospital, Seoul National University College of Medicine, 101, Daehak-ro, Jongno-gu, Seoul 03080, Korea

Tel: $+82-2-2072-2082$

Fax: +82-2-2072-3917

E-mail: nina337@snu.ac.kr https://orcid.org/0000-0001-91791247
Over the last decades, the onset of puberty in girls has occurred earlier, but the tempo of pubertal progression has been relatively slower, resulting in a younger age at puberty onset without a change in age at menarche. Sufficient energy availability and adiposity contribute to early pubertal development, and environmental factors, such as endocrine-disrupting chemicals (EDCs), may affect not only the control of energy balance, but also puberty and reproduction. EDCs are hormonally active substances that can perturb puberty by acting both peripherally on target organs, such as adipose tissue or adrenal glands, and/or centrally on the hypothalamic-pituitary-gonadal (HPG) axis. Depending on whether the exposure takes place earlier during fetal and neonatal life or later during early childhood, EDCs can lead to different outcomes through different mechanisms. Evidence of associations between exposures to EDCs and altered pubertal timing makes it reasonable to support their relationship. However, human epidemiologic data are limited or inconsistent and cannot provide sufficient evidence for a causal relationship between EDC exposure and changes in pubertal timing. Further investigation is warranted to determine the overall or different effects of EDCs exposure during prenatal or childhood windows on pubertal milestones and to reveal the underlying mechanisms, including epigenetic marks, whereby early-life exposure to EDCs affect the HPG-peripheral tissue axis.

Keywords: Puberty, Endocrine disrupting chemicals, Secular trend

\section{Introduction}

Puberty begins with the release of the hypothalamic gonadotropin-releasing hormone $(\mathrm{GnRH})$ pulse generator from central nervous system inhibition after a quiescent period during childhood. ${ }^{1)}$ The age of menarche has definitely decreased from 16 years in the 1800 s to 13 years in the 1960 s, after which this downward trend seems to have slowed or even stopped. ${ }^{2)}$ The trend for earlier age at menarche has also been reported in Korea, from 16.6 years for females born between 1925 and 1929 to 12.6 years for females born between 1990 and 1994. ${ }^{3,4)}$ While the onset of puberty has been occurring earlier, the overall tempo of pubertal progression is reported to be relatively slower, resulting in skewing towards younger ages for the onset of puberty and towards older ages for the completion of puberty. ${ }^{2)}$ Such increased duration of the pubertal transition may result from gonadotropin-independent estrogenic action at the level of the breast which may originate from peripheral tissues.

Although genetic factors remain the major determinant of pubertal timing, ${ }^{6}$ the secular trend for earlier onset of puberty has coincided with improved public health and nutrition. ${ }^{7-9)}$ Sufficient energy availability and early adiposity rebound contribute to early pubertal development. Endocrine-disrupting chemicals (EDCs) may affect not only the control of energy balance and adiposity, but also puberty and reproduction. ${ }^{2}$ EDCs can act at any level in the 'hypothalamic-pituitary-gonadal (HPG)-peripheral tissues' axis. ${ }^{10)}$ Their effects can 
manifest right before puberty as well as much earlier, during fetal and neonatal life. ${ }^{2)}$ We reviewed the genetic and environmental factors that have been implicated in pubertal timing. We present the current evidence for the roles of EDCs on pubertal timing in girls based on human epidemiologic data and introduce potential mechanisms depending on the timing of exposure.

\section{Factors implicated in pubertal timing by affecting the hypothalamic-pituitary-gonadal- peripheral tissues axis}

Pubertal onset appears to be a highly heritable trait, but earlier sexual maturation in girls may be linked to environmental factors. Some genes implicated in precocious puberty (DLK1, MKRN3, and KISS1) and in delayed puberty (TACR3) are associated with variations in pubertal onset. The childhood GnRH pulse generator may be inhibited, in part, by MKRN3. Disinhibition of the HPG axis leads to the progressive amplification of pulsatile GnRH secretion which may be mediated by leptin levels and increased expression of neuropeptides, such as neurokinin B and kisspeptin, and their receptors. ${ }^{1)}$ In addition to central signals, peripheral metabolic and nutritional signals, such as leptin and insulin, play a permissive role in the proper function of the HPG axis. ${ }^{11)}$

Genes involved in pubertal timing or menarche reported by Elks et al. ${ }^{12)}$ and Perry et al. ${ }^{13)}$ include those related to hypothalamic GnRH secretion, pituitary development and function, hormone synthesis and bioactivity, energy homeostasis and growth, and potential peripheral feedback from sex steroids. ${ }^{13)}$ The overlap of genes involved in pubertal onset and obesity from genome wide association studies and human epidemiological data suggests a common pathway connecting early infancy weight gain, earlier pubertal onset, and later obesity in adulthood, although mechanisms whereby earlylife changes in adiposity affect growth acceleration and early pubertal onset remain to be determined. ${ }^{14,15)}$

Obese girls are at risk for early pubertal development. Girls maturing at earlier ages have higher body mass index (BMI) $z$-scores with advanced Tanner stages. ${ }^{16)}$ Obesity-induced hyperinsulinemia and hyperleptinemia can affect linear growth and advance puberty. ${ }^{17)}$ Since adrenarche starts earlier as childhood BMI and insulin levels gradually increase, the increased adrenal androgen levels in obese children may also be responsible for accelerated growth before puberty. ${ }^{177}$ In addition, hyperinsulinemia can increase sex steroid bioavailability via stimulation of ovarian growth and steroidogenesis, reduction of sex hormone binding globulin, and increased conversion of androgens to estrogens by stimulating aromatase activity in adipose tissues. ${ }^{2}$ Breast development can occur from the gonadotropin-independent release of estrogen by peripheral tissues, such as the adrenal glands and adipose tissue. Finally, increased sex steroid levels in obese girls can induce gonadotropin-independent or dependent precocious puberty.

Gene-to-environment interactions during critical periods of development could alter gene expression in the HPG-peripheral tissue axis through epigenetic mechanisms. ${ }^{18)}$ While recent data have started to reveal the epigenetic regulation of KISSI expression, ${ }^{18,19)}$ epigenetic mechanisms that affect the HPGperipheral tissue axis remain to be discovered. The intrauterine environment, birth size, nutrition, and (potentially) EDCs can affect adiposity and the timing of puberty. EDCs and adiposity may be the most concerning contributors to changes in puberty and reproduction. While sufficient energy availability provides clues to the mechanism of early pubertal development, changes in the control of both energy balance and reproduction may vary under the influence of common determinants, such as EDCs. These effects can manifest right before puberty as well as much earlier during fetal and neonatal life. ${ }^{20,21)}$ Although the link between EDCs and pubertal timing does not prove causality, their association is highly suggestive. ${ }^{22}$

\section{Possible mechanisms for the effect of EDCs on pubertal timing in girls}

EDCs are defined as "an exogenous chemical, or mixture of chemicals, that interferes with any aspect of hormone action" by the Endocrine Society's second scientific statement published in 2015. ${ }^{10)}$ Endocrine disruptors can be naturally occurring or synthetic. This section reviews the effects of synthetic EDCs on pubertal timing in girls.

EDCs can act through several mechanisms at any level in the 'HPG-peripheral tissues' endocrine axis. Directly, EDCs may affect genes or HPG pathways unique to puberty. Indirectly, EDCs can act as obesogens and change metabolic programming during fetal and early childhood development, resulting in alterations in the metabolic and peripheral hormones associated with the onset of puberty. ${ }^{15)} \mathrm{A}$ variety of chemical toxins that are ubiquitously present in our environment exert antagonistic and agonistic actions on hormonal axes and pathways at low versus high concentrations, and they demonstrate nonmonotonic dose-response curves. ${ }^{10)}$ Since many EDCs can act as agonists of estrogen receptors (ERs) or antagonists of androgen receptors (ARs), EDCs may mimic naturally occurring estrogens and androgens. In addition, EDCs might bind to a receptor within a cell and block the functions of endogenous hormones, thus acting as antiestrogens and antiandrogens. ${ }^{10,23)}$

Low-level exposures to a mixture of EDCs may mask the effect of an individual compound. Moreover, interindividual and interspecies variation in susceptibility may be present due to differences in pharmacokinetics and/or genetic polymorphisms in key genes, complicating our ability to translate data from animal studies to human health. ${ }^{20)}$ In humans, the long interval from exposure to endpoints (latent effects) and the setting of mixed exposures over a lifetime make it difficult to analyze the health outcomes of EDCs. ${ }^{20)}$ Furthermore, it is difficult to distinguish the influence of nutrition and adiposity on pubertal outcomes from that of EDCs. Since the prenatal, neonatal, infancy, early childhood and peripubertal periods are critical windows of development, EDCs may have different effects depending on the time of exposure. ${ }^{2)}$ Though the mechanisms 
whereby fetal or neonatal life changes pubertal timing have not been fully elucidated, EDCs can alter the genes involved in the modification of epigenetic marks. ${ }^{2,15}$ Although researching the effect of EDCs on pubertal timing is difficult for the various aforementioned reasons, further investigation is warranted to determine which EDCs can affect pubertal timing, which periods of exposure are critical, and how different mechanisms are involved depending on the timing of exposure in humans. ${ }^{24)}$

\section{Human epidemiologic data on EDCs in regards to pubertal timing in girls}

The Endocrine Society's Scientific Statements present a review of the literature on human studies that assessed the associations between EDCs exposure and pubertal timing. ${ }^{10)}$ There have been extensive reviews about the contribution of EDCs on shifts in pubertal timing ${ }^{2,10,24,25)}$ as well as a recent review of publications from 2016 to 2017 that examined EDC associations with pubertal milestones. ${ }^{26)}$ The EDCs most extensively studied in regards to puberty include bisphenol A (BPA), phthalate esters, pesticides (dichlorodiphenyl trichloroethane [DDT], pyrethroids), dioxins and polychlorinated biphenyls (PCBs), and flame retardants (polybrominated biphenyls [PBB], polybrominated diphenyl ethers [PBDEs]) (Table 1). This section reviews the human epidemiologic studies regarding the relationship of individual EDCs with pubertal development or menarche in girls.

\section{Bisphenol A}

BPA is used in polycarbonate plastics, plastic bottles and toys, epoxy resins, dental sealants, and linings of food cans and has a half-life of 4 to 5 hours. ${ }^{27)}$ BPA has weak ER agonist activity at lower concentrations but can also compete with endogenous estrogens for binding, and they have antiandrogenic properties at higher concentrations. ${ }^{28)}$ Epidemiological studies on BPA and puberty have produced inconsistent results (Table 2). ${ }^{29-51)}$ Serum or urinary BPA concentrations were significantly associated with premature thelarche, ${ }^{39,51)}$ precocious puberty, ${ }^{32,37,44,50)}$ and earlier pubertal development. ${ }^{48)}$ However, other studies have reported no significant relationship ${ }^{29-31,33-36,38,40-43,47)}$ or later onset of puberty or menarche. ${ }^{45,46,49)}$ Although most previous studies for BPA and pubertal milestones were limited by cross-sectional or case-control study designs, 6 longitudinal studies have been reported. ${ }^{33,41,45,47-49)}$ Early childhood exposure to BPA showed no relationship to pubertal timing ${ }^{33,41,47)}$ or late onset of puberty. ${ }^{45)}$

Table 1. Chemical endocrine disruptors in regards to puberty in girls

\begin{tabular}{|c|c|c|c|c|c|c|c|}
\hline & BPA & Phthalates & DDT/DDE & Pyrethroids & Dioxin & PCBs & PBB/PBDE \\
\hline Group & Bisphenols & Plasticizers & Organochloride & Insecticide & $\begin{array}{l}\text { Polychlorinated } \\
\text { dibenzo-p-dioxin }\end{array}$ & Organochloride & Organohalogen \\
\hline $\begin{array}{l}\text { Introduction } \\
\text { date }\end{array}$ & $1960 \mathrm{~s}$ & $1920 \mathrm{~s}$ & $1940 \mathrm{~s}$ & $1960 \mathrm{~s}$ & 1872 & 1927 & 1970s \\
\hline $\begin{array}{l}\text { Restricted/ } \\
\text { Banned } \\
\text { date }\end{array}$ & Restricted 2012 & Restricted 2009 & Banned 1972 & Restricted & Banned 1979 & Banned 1979 & Restricted 2007 \\
\hline $\begin{array}{l}\text { Route of } \\
\text { exposure }\end{array}$ & $\begin{array}{c}\text { Ingestion, } \\
\text { dermal absorption, } \\
\text { inhalation }\end{array}$ & $\begin{array}{c}\text { Ingestion, } \\
\text { dermal absorption, } \\
\text { inhalation }\end{array}$ & $\begin{array}{c}\text { Ingestion, } \\
\text { dermal absorption, } \\
\text { inhalation }\end{array}$ & $\begin{array}{c}\text { Ingestion, } \\
\text { dermal abruption, } \\
\text { inhalation }\end{array}$ & $\begin{array}{l}\text { Ingestion, } \\
\text { inhalation }\end{array}$ & $\begin{array}{c}\text { Ingestion, } \\
\text { dermal absorption, } \\
\text { inhalation }\end{array}$ & $\begin{array}{c}\text { Ingestion, } \\
\text { dermal abruption, } \\
\text { inhalation }\end{array}$ \\
\hline Half-life & $4-5$ hours & 12 hours & $6-10$ years & 10 hours & 7-11 years & 12 days-16 years & 2 days -3 months \\
\hline Sources & $\begin{array}{l}\text { Polycarbonate } \\
\text { plastics, epoxy } \\
\text { resins, plastic toys } \\
\text { and bottles, lining } \\
\text { of food cans }\end{array}$ & $\begin{array}{l}\text { Contaminated } \\
\text { food, PVC plastics } \\
\text { and flooring, } \\
\text { personal care } \\
\text { products, medical } \\
\text { devices and } \\
\text { tubing }\end{array}$ & $\begin{array}{l}\text { Contaminated } \\
\text { water, soil crops, } \\
\text { fish }\end{array}$ & $\begin{array}{l}\text { Contaminated } \\
\text { water, soil, food }\end{array}$ & $\begin{array}{l}\text { By-product of } \\
\text { chlorinated } \\
\text { herbicide } \\
\text { production, } \\
\text { smelting, chlorine } \\
\text { bleaching of paper }\end{array}$ & $\begin{array}{l}\text { Contaminated } \\
\text { air and food, skin } \\
\text { contact with } \\
\text { old electrical } \\
\text { equipment }\end{array}$ & $\begin{array}{l}\text { Furniture, } \\
\text { mattresses, carpet } \\
\text { pads, automobile } \\
\text { seats, flame- } \\
\text { retardant textiles }\end{array}$ \\
\hline Mechanism & $\begin{array}{c}\text { ER agonist } \\
\text { Antiandrogen }\end{array}$ & $\begin{array}{l}\text { ER agonist (weak) } \\
\text { Antiandrogen } \\
\text { Interfere with } \\
\text { androgen } \\
\text { synthesis }\end{array}$ & $\begin{array}{l}\text { ER agonist } \\
\text { Antiandrogen } \\
\text { Antiprogestin }\end{array}$ & $\begin{array}{c}\text { Antiandrogen } \\
\text { (very weak) }\end{array}$ & $\begin{array}{l}\text { ER agonist (weak) } \\
\text { Antiandrogen } \\
\text { (weak) Interfere } \\
\text { with sex-steroid } \\
\text { (androgen/ } \\
\text { estrogen) } \\
\text { synthesis }\end{array}$ & $\begin{array}{c}\text { ER agonist/ } \\
\text { antagonist } \\
\text { Antiandrogen }\end{array}$ & $\begin{array}{c}\text { ER agonist/ } \\
\text { antagonist } \\
\text { Antiandrogen } \\
\text { (AR antagonist) }\end{array}$ \\
\hline $\begin{array}{l}\text { Effect on } \\
\text { puberty } \\
\text { in human } \\
\text { studies }\end{array}$ & $\begin{array}{l}\text { Several studies, } \\
\text { but inconsistent }\end{array}$ & $\begin{array}{l}\text { Several studies, } \\
\text { but inconsistent }\end{array}$ & $\begin{array}{l}\text { Several studies, } \\
\text { but inconsistent }\end{array}$ & $\begin{array}{l}\text { Limited } \\
\text { (only } 1 \text { study) }\end{array}$ & Limited & Limited & Limited \\
\hline
\end{tabular}

BPA, bisphenol A; DDT, dichlorodiphenyl trichloroethane; DDE, dichlorodiphenyl dichloroethylene; ER, estrogen receptor; AR, androgen receptor; PBB, polybrominated biphenyls; PBDE, polybrominated diphenyl ester; PCB, polychlorinated biphenyl; PVC, poly vinyl chloride. Modified from Gore AC, et al. Endocr Rev 2015;36:E1-E150, with permission of Oxford University Press. ${ }^{10)}$ 
Table 2. Human studies investigating the relationship of BPAs and phthalate metabolites with pubertal development in girls

\begin{tabular}{|c|c|c|c|c|c|c|}
\hline $\begin{array}{l}\text { Chemical } \\
\text { exposure } \\
\text { (biospecimen) }\end{array}$ & $\begin{array}{l}\text { Study population } \\
\text { (sample size) }\end{array}$ & Subjects age & Study design & $\begin{array}{l}\text { Correlation with } \\
\text { puberty }\end{array}$ & Findings & Reference \\
\hline Phthalate (serum) & $\begin{array}{c}\text { Puerto Rico } \\
\text { (41 with PT+35 } \\
\text { controls) }\end{array}$ & $\begin{array}{c}6 \text { months }-10 \text { years } \\
\text { old }\end{array}$ & $\mathrm{CC}$ & YES (early) & $\begin{array}{l}\text { Higher DBP, DEHP, and } \\
\text { MEHP levels in girls } \\
\text { with PT }\end{array}$ & Colon, 2000 \\
\hline Phthalate (serum) & $\begin{array}{l}\text { China (110 with } \\
\text { PP }+100 \text { controls) }\end{array}$ & $6-8$ years old & CC & YES (early) & $\begin{array}{l}\text { Higher DBP and DEHP } \\
\text { levels in girls with PP }\end{array}$ & Qiao, 20075) \\
\hline BPA (serum) & $\begin{array}{l}\text { Korea (50 with } \\
\text { PP+50 controls) }\end{array}$ & $8-11$ years old & CC & NO & $\begin{array}{l}\text { No significant } \\
\text { differences between } \\
\text { PP and control group } \\
\text { regarding BPA levels }\end{array}$ & Han, $2008^{29)}$ \\
\hline BPA (urine) & US (192) & 9 years old & $\begin{array}{c}\text { CS; assessed } \\
\text { pubertal status by } \\
\text { questionnaire and } \\
\text { examination }\end{array}$ & NO & $\begin{array}{l}\text { No effects of BPA on } \\
\text { pubertal status }\end{array}$ & Wolff, 2008 \\
\hline Phthalate (urine) & $\begin{array}{c}\text { Taiwan } \\
\text { (30 with PT+ } \\
26 \text { with CPP+ } \\
33 \text { controls) }\end{array}$ & $6-9$ years old & $\mathrm{CC}$ & YES (early) & $\begin{array}{l}\text { Higher MMP levels in } \\
\text { girls with PT }\end{array}$ & Chou, 2009 \\
\hline $\begin{array}{l}\text { BPA/Phthalate } \\
\text { (serum) }\end{array}$ & $\begin{array}{c}\text { Korea } \\
\text { (29 with CPP+ } \\
29 \text { controls) }\end{array}$ & & CC & $\begin{array}{c}\text { NO (BPA)/YES } \\
\text { (phthalate, early) }\end{array}$ & $\begin{array}{c}\text { No significant } \\
\text { differences between } \\
\text { CPP and control } \\
\text { groups regarding BPA } \\
\text { levels/higher DEHP } \\
\text { levels in girls with CPP }\end{array}$ & Lee, $2009^{31)}$ \\
\hline BPA (serum) & $\begin{array}{l}\text { China (110 with } \\
\text { PP }+100 \text { controls) }\end{array}$ & $6-8$ years old & CC & YES (early) & $\begin{array}{l}\text { Higher BPA levels in } \\
\text { girls with CPP }\end{array}$ & Qiao, 2010 32) \\
\hline $\begin{array}{l}\text { BPA/Phthalate } \\
\text { (urine at } \\
\text { enrollment) }\end{array}$ & $\begin{array}{c}\text { US, BCERP cohort } \\
(1,151)\end{array}$ & $6-8$ years old & $\begin{array}{l}\text { C (1-year follow- } \\
\text { up); assessed Tanner } \\
\text { stages by inspection } \\
\text { and palpation }\end{array}$ & $\begin{array}{l}\text { NO (BPA)/YES (high- } \\
\text { molecular-weight- } \\
\text { phthalates, late vs. } \\
\text { low-molecular- } \\
\text { weight-phthalates, } \\
\text { early) }\end{array}$ & $\begin{array}{l}\text { No effects of BPA on } \\
\text { breast or public hair } \\
\text { development/High- } \\
\text { molecular-weight- } \\
\text { phthalates levels } \\
\text { were associated } \\
\text { with late pubic hair } \\
\text { development, while } \\
\text { low-molecular- } \\
\text { weight-phthalates } \\
\text { levels with advanced } \\
\text { breast/pubic hair } \\
\text { development }\end{array}$ & Wolff, 2010 $0^{33)}$ \\
\hline $\begin{array}{l}\text { BPA/Phthalate } \\
\text { (urine) }\end{array}$ & $\begin{array}{l}\text { US, NHANES 2003- } \\
2008(461)\end{array}$ & $12-16$ years old & $\begin{array}{c}\text { CS; assessed age at } \\
\text { menarche }\end{array}$ & NO (both) & $\begin{array}{l}\text { No effects of BPA } \\
\text { levels or total } \\
\text { phthalate metabolite } \\
\text { levels on the age of } \\
\text { menarche }\end{array}$ & Buttke, 2012 \\
\hline $\begin{array}{l}\text { Phthalate } \\
\text { (urine) }\end{array}$ & $\begin{array}{l}\text { Denmark (Total } \\
725 \text { girls, } 24 \text { with } \\
\text { PP+184 controls) }\end{array}$ & $5-19$ years old & $\begin{array}{l}\text { CS or CC; assessed } \\
\text { pubertal stages by } \\
\text { clinical examination }\end{array}$ & NO & $\begin{array}{l}\text { MBzP and MBP levels } \\
\text { were associated } \\
\text { with late pubarche, } \\
\text { not associated } \\
\text { with thelarche } \\
\text { No significant } \\
\text { differences between } \\
\text { PP and control group } \\
\text { regarding phthalate } \\
\text { metabolite levels }\end{array}$ & $\begin{array}{l}\text { Frederiksen, } \\
2012^{57)}\end{array}$ \\
\hline
\end{tabular}

BCERP, the Breast Cancer and the Enviroment Reaserch Program; BPA, bisphenol A; BMI, body mass index; C, cohort study; CC, case-control study; CHAMACOS, the Center for the Health Assessment of Mothers and Children of Salinas; CPP, central precocious puberty; CS, crosssectional study; DBP, dibutyl phthalate; DEHP, di-2-ethylhexyl phthalate; MBP, mono-n-butyl phthalate; MBzP, mono-benzyl phthalate; MCPP, mono-3-carboxypropyl phthalate; MEHP, mono-2-ethylhexyl phthalate; MEHHP, mono-(2-ethyl-5-hydroxyhexyl) phthalate; MEOHP, mono-(2-ethyl-5-oxohexyl) phthalate; MEP, mono-ethyl phthalate; MMP, monomethyl phthalate; NHANES, The National Health and Nutrition Examination Survey; PP, precocious puberty; PPP, peripheral precocious puberty; PT, premature thelarche; US, United States. 
Table 2. Human studies investigating the relationship of BPAs and phthalate metabolites with pubertal development in girls (continued)

\begin{tabular}{|c|c|c|c|c|c|c|}
\hline $\begin{array}{l}\text { Chemical } \\
\text { exposure } \\
\text { (biospecimen) } \\
\end{array}$ & $\begin{array}{l}\text { Study population } \\
\text { (sample size) }\end{array}$ & Subjects age & Study design & $\begin{array}{l}\text { Correlation with } \\
\text { puberty }\end{array}$ & Findings & Reference \\
\hline Phthalate (urine) & $\begin{array}{l}\text { Taiwan (73 with CPP } \\
\quad+31 \text { controls) }\end{array}$ & 2-11 years old & CC & YES (early) & $\begin{array}{l}\text { Higher phthalate } \\
\text { metabolite (MEP, } \\
\text { MBzP, MEHHP, and } \\
\text { MEOHP) levels in girls } \\
\text { with CPP }\end{array}$ & Chen, 2013 \\
\hline BPA (urine) & Denmark (129) & $6-21$ years old & $\begin{array}{l}\text { CS; assessed } \\
\text { pubertal status by } \\
\text { clinical examination } \\
\text { or questionnaire }\end{array}$ & NO & $\begin{array}{c}\text { No effects of } \\
\text { BPA on pubertal } \\
\text { developmental stage }\end{array}$ & $\begin{array}{l}\text { Frederiksen, } \\
2013^{35)}\end{array}$ \\
\hline $\begin{array}{l}\text { Phthalate (urine at } \\
\text { enrollment and at } \\
\text { follow-up) }\end{array}$ & Denmark (84) & $5-12$ years old & $\begin{array}{l}\text { C (follow-up every } 6 \\
\text { months for } 5 \text { years); } \\
\text { assessed Tanner } \\
\text { stages to determine } \\
\text { age at puberty }\end{array}$ & NO & $\begin{array}{c}\text { No effects of phthalate } \\
\text { on the age of pubertal } \\
\text { development }\end{array}$ & Mouritsen, $2013^{59)}$ \\
\hline $\begin{array}{l}\text { BPA/Phthalate } \\
\text { (serum) }\end{array}$ & $\begin{array}{l}\text { Korea (150 with PP } \\
\quad+90 \text { controls) }\end{array}$ & $6-12$ years old & CC & $\begin{array}{c}\text { NO (BPA)/YES } \\
\text { (phthalate, early) }\end{array}$ & $\begin{array}{l}\text { No significant } \\
\text { differences between } \\
\text { PP group and control } \\
\text { group regarding BPA } \\
\text { levels/Higher MBP } \\
\text { levels in girls with PP }\end{array}$ & Yum, $2013^{36)}$ \\
\hline BPA (urine) & $\begin{array}{l}\text { Turkey (28 with CPP } \\
\quad+25 \text { controls) }\end{array}$ & $4-8$ years old & CC & YES (early) & $\begin{array}{l}\text { Higher BPA levels in } \\
\text { girls with CPP }\end{array}$ & Durmaz, 2014 \\
\hline BPA (urine) & $\begin{array}{l}\text { Korea (42 with CPP } \\
+40 \text { with PPP+ } \\
37 \text { controls) }\end{array}$ & 7-9 years old & CC & NO & $\begin{array}{c}\text { No significant } \\
\text { differences between } \\
\text { PP group and control } \\
\text { group regarding BPA } \\
\text { levels }\end{array}$ & Lee, $2014^{38)}$ \\
\hline $\begin{array}{l}\text { Phthalate } \\
\text { (urine at } \\
\text { enrollment) }\end{array}$ & $\begin{array}{l}\text { US, BCERP cohort } \\
(1,239)\end{array}$ & $6-8$ years old & $\begin{array}{c}\text { C (follow-up until } \\
\text { breast and pubic } \\
\text { hair development); } \\
\text { pubertal status } \\
\text { examination 1-2 } \\
\text { times/year }\end{array}$ & YES (late) & $\begin{array}{l}\text { Higher exposure } \\
\text { to high-molecular- } \\
\text { weight-phthalates } \\
\text { (DEHP) was associated } \\
\text { with later pubarche }\end{array}$ & Wolff, 2014 \\
\hline BPA (serum) & $\begin{array}{l}\text { China (251 with PT } \\
\text { +33 controls) }\end{array}$ & $\begin{array}{c}4 \text { months }-2 \text { years } \\
\text { old }\end{array}$ & $\begin{array}{l}\text { CC; PT in female } \\
\text { infants }\end{array}$ & YES (early) & $\begin{array}{l}\text { Higher BPA levels in } \\
\text { girl with PT }\end{array}$ & Chen, 2015 \\
\hline BPA (urine) & $\begin{array}{c}\text { US, NHANES } \\
\text { 2003-2010 (987) }\end{array}$ & 12-19 years old & $\begin{array}{l}\text { CS; assessed age } \\
\text { at menarche by } \\
\text { questionnaire }\end{array}$ & NO & $\begin{array}{c}\text { BPA level was } \\
\text { associated with } \\
\text { delayed menarche } \\
\text { (not statistically } \\
\text { significant) }\end{array}$ & McGuinn, 2015 \\
\hline $\begin{array}{l}\text { BPA } \\
\text { (urine at } \\
\text { enrollment) }\end{array}$ & $\begin{array}{l}\text { US, BCERP cohort } \\
\quad(1,239 \text { girls })\end{array}$ & $6-8$ years old & $\begin{array}{c}\text { C (follow-up for } \\
\text { 7-year); annual } \\
\text { pubertal assessment }\end{array}$ & NO & $\begin{array}{c}\text { No association } \\
\text { between pubertal } \\
\text { development and BPA } \\
\text { levels }\end{array}$ & Wolff, 2015 ${ }^{41)}$ \\
\hline $\begin{array}{l}\text { Phthalate (urine at } \\
\text { enrollment and at } \\
\text { follow-up) }\end{array}$ & China (208) & $6-13$ years old & $\begin{array}{l}\text { CS or C; assessed } \\
\text { pubertal } \\
\text { development state } \\
\text { at } 18 \text { months of } \\
\text { follow-up }\end{array}$ & YES (early) & $\begin{array}{c}\text { Phthalate levels (MBP, } \\
\text { MMP, MEP, and MEHP) } \\
\text { were associated } \\
\text { with higher breast } \\
\text { development stage, } \\
\text { earlier menarche, and } \\
\text { speedup in breast } \\
\text { progression }\end{array}$ & Zhang, 2015 $5^{61)}$ \\
\hline
\end{tabular}

BCERP, the Breast Cancer and the Enviroment Reaserch Program; BPA, bisphenol A; BMI, body mass index; C, cohort study; CC, case-control study; CHAMACOS, the Center for the Health Assessment of Mothers and Children of Salinas; CPP, central precocious puberty; CS, crosssectional study; DBP, dibutyl phthalate; DEHP, di-2-ethylhexyl phthalate; MBP, mono-n-butyl phthalate; MBzP, mono-benzyl phthalate; MCPP, mono-3-carboxypropyl phthalate; MEHP, mono-2-ethylhexyl phthalate; MEHHP, mono-(2-ethyl-5-hydroxyhexyl) phthalate; MEOHP, mono-(2-ethyl-5-oxohexyl) phthalate; MEP, mono-ethyl phthalate; MMP, monomethyl phthalate; NHANES, The National Health and Nutrition Examination Survey; PP, precocious puberty; PPP, peripheral precocious puberty; PT, premature thelarche; US, United States. 
Table 2. Human studies investigating the relationship of BPAs and phthalate metabolites with pubertal development in girls (continued)

\begin{tabular}{|c|c|c|c|}
\hline $\begin{array}{l}\text { Chemical } \\
\text { exposure } \\
\text { (biospecimen) }\end{array}$ & $\begin{array}{l}\text { Study population } \\
\text { (sample size) }\end{array}$ & Subjects age & Study design \\
\hline $\begin{array}{l}\text { BPA (urine)/ } \\
\text { Phthalate } \\
\text { (plasma) }\end{array}$ & $\begin{array}{c}\text { Turkey (42 with CPP } \\
+42 \text { with PPP+ } \\
50 \text { controls) }\end{array}$ & $6-8$ years old & CC \\
\hline
\end{tabular}

$\begin{gathered}\text { Correlation with } \\ \text { puberty }\end{gathered}$ Findings Reference
NO

\begin{tabular}{|c|c|c|c|c|}
\hline BPA (urine) & $\begin{array}{l}\text { Turkey (28 with CPP } \\
+28 \text { with PT+ } \\
22 \text { controls) }\end{array}$ & $5-8$ years old & CC & NO \\
\hline BPA (urine) & $\begin{array}{l}\text { Thailand ( } 41 \text { with PP } \\
+47 \text { controls) }\end{array}$ & $6-8$ years old & $\mathrm{CC}$ & Yes (early) \\
\hline
\end{tabular}

\begin{tabular}{|c|c|c|c|c|}
\hline $\begin{array}{l}\text { BPA/Phthalate } \\
\text { (urine at } \\
\text { enrollment) }\end{array}$ & Germany (222) & $8-10$ years old & $\begin{array}{c}\text { C (3-year follow-up); } \\
\text { annually follow } \\
\text { up for pubertal } \\
\text { development scale } \\
\text { questionnaires }\end{array}$ & YES (both, late) \\
\hline BPA (urine) & China (655) & $9-18$ years old & $\begin{array}{l}\text { CS; assessed pubertal } \\
\text { development by } \\
\text { Tanner staging and } \\
\text { self-reported age at } \\
\text { menarche }\end{array}$ & $\begin{array}{l}\text { YES (early pubarche, } \\
\text { late menarche) }\end{array}$ \\
\hline
\end{tabular}

$\begin{array}{lcc}\text { Phthalate (urine) } & \begin{array}{c}\text { Thailand (42 with } \\ \text { PP+17 with early } \\ \text { puberty+ } \\ 77 \text { controls) }\end{array} \\ & \begin{array}{c}71 \text { years old } \\ \text { UPA, BCERP cohort } \\ \text { (urine at } \\ \text { enrollment) }\end{array} & \text { 6-8 years old } \\ & \end{array}$

NO (BPA)/YES No differences

between CPP, PPP

and control groups regarding BPA levels/ Higher DEHP and MEHP levels in girls with CPP than those with PPP or controls

$\begin{array}{cc}\text { No differences } & \text { Ozgen, } 2016^{43)} \\ \text { between CPP, PT } & \\ \text { and control groups } & \\ \text { regarding BPA levels } & \\ \text { Higher BPA levels in } & \text { Supornsilchai, } \\ \text { girl with PP especially } & 2016^{44)}\end{array}$

in overweight or obese group

BPA or phthalate Kasper-
metabolites (DEHP Sonnenberg, metabolites, MBP, $\quad 2017^{45)}$ and MEP) levels were associated with delayed pubertal development

BPA exposures were Miao, 201746) associated with delayed menarche while with earlier onset of pubarche Higher MEP Ievels Srilanchakon, girls with PP than 2017 those of controls

\section{C (11-year follow-up); annual pubertal assessment, self- reported age at menarche} NO (BPA)/YES
(phthalate, late)

No association between pubertal development or menarche and BPA/ Higher MCPP levels were associated with later age of thelarche and menarche

\begin{tabular}{|c|c|c|c|c|}
\hline $\begin{array}{l}\text { BPA/Phthalate } \\
\text { (maternal urine, } \\
\text { 1st, 2nd, and 3rd } \\
\text { trimester) }\end{array}$ & Mexico (120) & 8-13 years & $\begin{array}{c}\text { C; assessed } \\
\text { Tanner staging by } \\
\text { examination }\end{array}$ & $\begin{array}{l}\text { YES (BPA of 2nd } \\
\text { trimester, early)/YES } \\
\text { (phthalate, whole } \\
\text { pregnancy, late) }\end{array}$ \\
\hline
\end{tabular}

Prenatal BPA of the

2nd trimester was

positively associated with thelarche /

Prenatal MEHP across pregnancy was negatively associated with thelarche, while MEHP of 3rd trimester was positively associated with

BCERP, the Breast Cancer and the Enviroment Reaserch Program; BPA, bisphenol A; BMI, body mass index; C, cohort study; CC, case-control study; CHAMACOS, the Center for the Health Assessment of Mothers and Children of Salinas; CPP, central precocious puberty; CS, crosssectional study; DBP, dibutyl phthalate; DEHP, di-2-ethylhexyl phthalate; MBP, mono-n-butyl phthalate; MBzP, mono-benzyl phthalate; MCPP, mono-3-carboxypropyl phthalate; MEHP, mono-2-ethylhexyl phthalate; MEHHP, mono-(2-ethyl-5-hydroxyhexyl) phthalate; MEOHP, mono-(2-ethyl-5-oxohexyl) phthalate; MEP, mono-ethyl phthalate; MMP, monomethyl phthalate; NHANES, The National Health and Nutrition Examination Survey; PP, precocious puberty; PPP, peripheral precocious puberty; PT, premature thelarche; US, United States. 
Table 2. Human studies investigating the relationship of BPAs and phthalate metabolites with pubertal development in girls (continued)

\begin{tabular}{|c|c|c|c|c|c|c|}
\hline $\begin{array}{l}\text { Chemical } \\
\text { exposure } \\
\text { (biospecimen) }\end{array}$ & $\begin{array}{l}\text { Study population } \\
\text { (sample size) }\end{array}$ & Subjects age & Study design & $\begin{array}{l}\text { Correlation with } \\
\text { puberty }\end{array}$ & Findings & Reference \\
\hline $\begin{array}{l}\text { BPA/Phthalate } \\
\text { (maternal urine, } \\
\text { at } 14.0 \text { and } 26.9 \\
\text { weeks' gestation) }\end{array}$ & $\begin{array}{l}\text { US, CHAMACOS } \\
\text { cohort (179) }\end{array}$ & 9-13 years old & $\begin{array}{c}\text { C (follow-up } \\
\text { every } 9 \text { months } \\
\text { between } 9-13 \text { years } \\
\text { of age); assessed } \\
\text { Tanner staging by } \\
\text { examination }\end{array}$ & $\begin{array}{l}\text { YES (BPA / phthalate, } \\
\text { late) }\end{array}$ & $\begin{array}{l}\text { Prenatal BPA levels } \\
\text { and phthalate (DEHP } \\
\text { metabolites and } \\
\text { MBzP) were associated } \\
\text { with later onset of } \\
\text { puberty (thelarche, } \\
\text { menarche, or } \\
\text { pubarche) in normal } \\
\text { weight girls }\end{array}$ & Berger, 2018 $8^{49)}$ \\
\hline $\begin{array}{l}\text { Phthalate (urine } \\
\text { at enrollment and } \\
\text { last follow-up) }\end{array}$ & Chile (200) & $6-9$ years old & $\begin{array}{l}\text { C (follow-up every } \\
6 \text { months from } \\
\text { Tanner } 1 \text { to } 4 \text { breast } \\
\text { development); } \\
\text { assessed age at } \\
\text { menarche }\end{array}$ & $\begin{array}{c}\text { YES } \\
\text { (pre-pubertal DEHP, } \\
\text { late/pubertal MMP, } \\
\text { early) }\end{array}$ & $\begin{array}{l}\text { Prepubertal DEHP } \\
\text { metabolite levels } \\
\text { were associated with } \\
\text { later menarche, while } \\
\text { pubertal MMP levels } \\
\text { were associated with } \\
\text { earlier menarche }\end{array}$ & Binder, 2018 \\
\hline BPA (urine) & $\begin{array}{l}\text { China (136 with CPP } \\
\quad+136 \text { controls) }\end{array}$ & 6-9 years old & $\mathrm{CC}$ & YES (early) & $\begin{array}{l}\text { Higher BPA levels in } \\
\text { girls with CPP }\end{array}$ & Chen, 2018 \\
\hline BPA (urine) & $\begin{array}{l}\text { Turkey ( } 25 \text { with PT } \\
+25 \text { controls) }\end{array}$ & $4-8$ years old & CC & YES (early) & $\begin{array}{l}\text { Higher BPA levels in } \\
\text { girl with PT }\end{array}$ & Durmaz, $2018^{51)}$ \\
\hline Phthalate (urine) & $\begin{array}{l}\text { Turkey (29 with PT } \\
\quad+25 \text { controls) }\end{array}$ & $4-8$ years old & CC & YES (early) & $\begin{array}{l}\text { Higher MEHP levels in } \\
\text { girls with PT }\end{array}$ & Durmaz, $2018^{64)}$ \\
\hline Phthalate (serum) & $\begin{array}{l}\text { Iran (87 with PP } \\
+63 \text { controls) }\end{array}$ & 7-9 years old & CC & YES (early) & $\begin{array}{l}\text { Higher DEHP levels in } \\
\text { girls with PP }\end{array}$ & $\begin{array}{l}\text { Hashemipour, } \\
2018^{55)}\end{array}$ \\
\hline
\end{tabular}

BCERP, the Breast Cancer and the Enviroment Reaserch Program; BPA, bisphenol A; BMI, body mass index; C, cohort study; CC, case-control study; CHAMACOS, the Center for the Health Assessment of Mothers and Children of Salinas; CPP, central precocious puberty; CS, crosssectional study; DBP, dibutyl phthalate; DEHP, di-2-ethylhexyl phthalate; MBP, mono-n-butyl phthalate; MBzP, mono-benzyl phthalate; MCPP, mono-3-carboxypropyl phthalate; MEHP, mono-2-ethylhexyl phthalate; MEHHP, mono-(2-ethyl-5-hydroxyhexyl) phthalate; MEOHP, mono-(2-ethyl-5-oxohexyl) phthalate; MEP, mono-ethyl phthalate; MMP, monomethyl phthalate; NHANES, The National Health and Nutrition Examination Survey; PP, precocious puberty; PPP, peripheral precocious puberty; PT, premature thelarche; US, United States.

Prenatal exposure was associated with earlier thelarche, ${ }^{48)}$ but rather later thelarche, pubarche, and menarche. ${ }^{49)}$ Recently in 2017 , a critical review on the effect of BPA on puberty ${ }^{52)}$ concluded that the current available data cannot establish a clear role for BPA in pubertal development due to conflicting results among the clinical and epidemiological studies examined.

\section{Phthalates}

Phthalates are used as liquid plasticizers in plastics and flooring, personal care products, medical devices and tubing with half-lives of 12 hours. Although the mechanism remains to be further elucidated, phthalates might act as ER agonists or AR antagonists and may also interfere with androgen synthesis. ${ }^{53)}$ Phthalates may be classified into low-molecularweight phthalates (ester side-chain lengths, 1 to 4 carbons) and high-molecular-weight-phthalates (ester side-chain lengths, 5 or more carbons). Di(2-ethylhexyl) phthalate (DEHP) metabolites (mono(2-ethyl-5-oxohexyl) phthalate and mono(2ethyl-5-hydroxyhexyl) phthalate), which are classified into high-molecular-weight-metabolites, were the phthalates most commonly studied.

The results from studies regarding the relationship between phthalate and puberty in girls conflict depending on the timing of exposure and/or different phthalate metabolites (Table 2). ${ }^{31}$, 33,34,36,42,45,47-49,54-65) Different studies have shown significant associations with premature thelarche $e^{54,56)}$ and precocious or early puberty, ${ }_{31,36,42,55,58,61,62,64,65)}$ while no relationship with puberty ${ }^{34,57,59)}$ or an association with later onset of puberty ${ }^{45,47-49,60)}$ have also been reported. Among several studies on phthalate exposure, nine studies had a longitudinal cohort design. ${ }^{33,45,47-49,59-61,63)}$ Prenatal exposure to high-molecularweight phthalate metabolites was associated with later onset of puberty. ${ }^{48)}$ Early childhood exposure to phthalate metabolites was not associated to puberty ${ }^{59)}$ or associated with earlier ${ }^{61)}$ or later ${ }^{45,47,49,60)}$ pubertal progression. Meanwhile, differences in pubertal development or age at menarche has been reported depending on the timing of exposure or classes of exposures (high or low-molecular-weight-phthalates). ${ }^{33,63)}$ Whereas highmolecular-weight phthalate levels were associated with later pubic hair development, low-molecular-weight phthalate levels were related to advanced breast or pubic hair development. ${ }^{33)}$ While prepubertal exposure to DEHP was associated with later menarche, pubertal exposure to monomethyl phthalate (lowmolecular-weight) was related to earlier menarche only among overweight or obese girls and not among those that were of 
normal weight. ${ }^{63)}$

\section{Pesticides}

Pesticides are substances used to kill or reduce the quantity of insects, weeds, rodents, or fungi. They are classified as insecticides, herbicides, fungicides, and rodenticides depending on their target. While over 100 pesticides are identified as EDCs, DDT and its metabolite dichlorodiphenyl dichloroethane (DDE) are the most extensively studied compounds. ${ }^{66)}$ DDT/
DDE have estrogenic, antiandrogenic, and antiprogestin effects. ${ }^{67)}$ DDT is a persistent organic pollutant with a half-life of 6-10 years. Although many, but not all, countries have banned organochlorine pesticides, it is insoluble in water and very persistent in the environment. ${ }^{68,69)}$ The results of human studies on the relationship between DDT exposure and puberty are inconsistent (Table 3$)^{30,70-78)}$; results have ranged from no relation to puberty ${ }^{30,72,73,75,78)}$ to associations with precocious puberty, ${ }^{74)}$ earlier age at menarche, ${ }^{70,71)}$ and later onset of puberty. ${ }^{76,77)}$ Three longitudinal studies have revealed that higher exposure to DDE

Table 3. Human studies regarding the relationship of pyrethroids, DDT/DDE, dioxins, PCBs, and flame retardants with pubertal development in girls

\begin{tabular}{|c|c|c|c|c|c|c|}
\hline $\begin{array}{l}\text { Chemical } \\
\text { exposure } \\
\text { (biospecimen) }\end{array}$ & $\begin{array}{l}\text { Study population } \\
\text { (sample size) }\end{array}$ & Subject age & Study design & $\begin{array}{l}\text { Correlation with } \\
\text { puberty }\end{array}$ & Finding & References \\
\hline $\begin{array}{l}\text { PBB } \\
\text { (maternal serum, } \\
\text { breast milk) }\end{array}$ & US (327) & $5-24$ years old & $\begin{array}{l}\text { C; assessed Tanner } \\
\text { stage and age } \\
\text { at menarche by } \\
\text { questionnaire }\end{array}$ & YES (early) & $\begin{array}{l}\text { Perinatal PBB exposure } \\
\text { was associated with earlier } \\
\text { pubic hair stage and } \\
\text { earlier age at menarche in }\end{array}$ & Blanck, 2000 \\
\hline
\end{tabular}

$\begin{array}{lcccc}\begin{array}{l}\text { TCDD/PCBs } \\ \text { (serum) }\end{array} & \text { Belgium (120) } & \text { 16-18 years old } & \begin{array}{c}\text { CS; assessed Tanner } \\ \text { stage }\end{array} & \text { YES (TCDD, late) } \\ \begin{array}{l}\text { DDE/PCBs } \\ \text { (maternal serum) }\end{array} & \text { US (151) } & 20-50 \text { years old } & \begin{array}{c}\text { C; assessed age } \\ \text { at menarche by } \\ \text { questionnaire }\end{array} & \text { YES (DDE, early)/ } \\ \text { NO (PCBs) }\end{array}$

Higher serum dioxin

levels were associated with delayed breast development

Higher prenatal DDE Vasiliu, 2004

levels were associated

with younger age at menarche/Prenatal PCB

levels were not associated with age at menarche

\begin{tabular}{|c|c|c|c|c|c|c|}
\hline $\begin{array}{l}\text { TCDD } \\
\text { (serum soon after } \\
\text { exposure) }\end{array}$ & Italy (282) & $\begin{array}{l}1 \text { month to } \\
40 \text { years } \\
\text { (premenarcheal } \\
\text { at exposure) }\end{array}$ & $\begin{array}{l}\text { C; assessed age } \\
\text { at menarche by } \\
\text { interview }\end{array}$ & NO & $\begin{array}{l}\text { TCDD exposure was } \\
\text { not related to age at } \\
\text { menarche }\end{array}$ & Warner, 2004 ${ }^{86)}$ \\
\hline DDT (serum) & China (446) & 20-34 years old & $\begin{array}{l}\text { CS; assessed age } \\
\text { at menarche by } \\
\text { interview }\end{array}$ & YES (early) & $\begin{array}{l}\text { The mean age at } \\
\text { menarche was younger } \\
\text { in the highest DDT } \\
\text { concentration quartile }\end{array}$ & Ouyang, $2005^{71)}$ \\
\hline DDE/PCBs (serum) & $\begin{array}{c}\text { Akwesasne } \\
\text { Mohawk Nation } \\
\text { (138) }\end{array}$ & $10-16$ years old & $\begin{array}{c}\text { CS; assessed } \\
\text { menarche status by } \\
\text { interview }\end{array}$ & $\begin{array}{l}\text { NO (DDE)/ } \\
\text { YES (PCBs, early) }\end{array}$ & $\begin{array}{l}\text { No association between } \\
\text { DDE level and menarche } \\
\text { status/PCB levels were } \\
\text { significant predictors of } \\
\text { reaching menarche }\end{array}$ & Denham, $2005^{72)}$ \\
\hline DDE (plasma) & US (192) & 9 years old & $\begin{array}{c}\text { CS; assessed } \\
\text { pubertal status by } \\
\text { questionnaire and } \\
\text { examination }\end{array}$ & NO & $\begin{array}{l}\text { No effects of plasma DDE } \\
\text { levels on breast stage }\end{array}$ & Wolff, 2008 30 ) \\
\hline $\begin{array}{l}\text { PCDD/F } \\
\text { PCBs, PBDE } \\
\text { (breast milk, } \\
\text { child serum) }\end{array}$ & Netherland (19) & 14-19 years old & $\begin{array}{l}\text { C; assessed age at } \\
\text { thelarche, pubarche, } \\
\text { and menarche by } \\
\text { questionnaire }\end{array}$ & $\begin{array}{l}\text { YES (PCDD/F, late)/ } \\
\text { NO (PCBs, PBDE) }\end{array}$ & $\begin{array}{c}\text { Prenatal PCDD/F } \\
\text { exposure was associated } \\
\text { with delayed breast } \\
\text { development/No } \\
\text { association between PCBs } \\
\text { or PBDE and pubertal } \\
\text { development }\end{array}$ & Leijs, $2008^{87)}$ \\
\hline
\end{tabular}

BCERP, the Breast Cancer and the Environment Research Program; BMI, body mass index; C, cohort study; CC, case-control study; CHAMACOS, the Center for the Health Assessment of Mothers and Children of Salinas; CS, cross-sectional study; DDE, dichlorodiphenyl dichloroethane; DDT, dichlorodiphenyl trichloroethane; NHANES, The National Health and Nutrition Examination Survey; PBB, polybrominated biphenyl; PBDE, polybrominated diphenyl ether; PCBs, polychlorinated biphenyl; PCDD, polychlorinated dibenzodioxins; PCDF, polychlorinated dibenzofurans; PP, precocious puberty; PT, premature thelarche; TCDD, tetrachlorodibenzo-p-dioxin; UK, United Kingdom; US, United States; 3-PBA, 3-phenoxybenzoic acid. 
Table 3. Human studies regarding the relationship of pyrethroids, DDT/DDE, dioxins, PCBs, and flame retardants with pubertal development in girls (continued)

\begin{tabular}{|c|c|c|c|c|}
\hline $\begin{array}{l}\text { Chemical } \\
\text { exposure } \\
\text { (biospecimen) }\end{array}$ & $\begin{array}{l}\text { Study population } \\
\text { (sample size) }\end{array}$ & Subject age & Study design & $\begin{array}{l}\text { Correlation with } \\
\text { puberty }\end{array}$ \\
\hline $\begin{array}{l}\text { PCDD/F } \\
\text { PCBs, PBDE } \\
\text { (breast milk, } \\
\text { child serum) }\end{array}$ & Netherland (19) & 14-19 years old & $\begin{array}{l}\text { C; assessed age at } \\
\text { thelarche, pubarche, } \\
\text { and menarche by } \\
\text { questionnaire }\end{array}$ & $\begin{array}{c}\text { YES (PCDD/F, late)/ } \\
\text { NO (PCBs, PBDE) }\end{array}$ \\
\hline PBDE (serum) & $\begin{array}{c}\text { US, } \\
\text { NHANES 2003-2004 } \\
(271)\end{array}$ & 12-19 years old & $\begin{array}{l}\text { CS; assessed age } \\
\text { at menarche by } \\
\text { questionnaire }\end{array}$ & YES (early) \\
\hline DDE/PCBs (serum) & $\begin{array}{l}\text { Belgium } \\
(792)\end{array}$ & $14-15$ years old & $\begin{array}{l}\text { CS; assessed } \\
\text { pubertal status by } \\
\text { Tanner stage and } \\
\text { age at menarche }\end{array}$ & $\begin{array}{l}\text { NO (DDE)/ } \\
\text { YES (PCBs, late) }\end{array}$ \\
\hline
\end{tabular}

\begin{tabular}{|c|c|c|c|c|c|c|}
\hline DDE (serum) & $\begin{array}{c}\text { China } \\
\text { (76 with PP+ } \\
99 \text { controls) }\end{array}$ & 3-9 years old & CC & YES (early) & $\begin{array}{l}\text { Higher positive rate of } \\
\text { DDE in PP group }\end{array}$ & Deng, $2012^{74)}$ \\
\hline $\begin{array}{l}\text { DDE } \\
\text { (serum, } \\
\text { adipose tissue) }\end{array}$ & $\begin{array}{c}\text { Turkey } \\
\text { (45 with PT+16 with } \\
\text { PP+33 controls) }\end{array}$ & $4-8$ years old & CC & NO & $\begin{array}{l}\text { Presence and levels } \\
\text { of DDT/DDE were not } \\
\text { associated with PP }\end{array}$ & Ozen, 2012 $2^{75)}$ \\
\hline $\begin{array}{l}\text { DDE/PCBs/ } \\
\text { PBDE (serum at } \\
\text { enrollment, } \\
\text { peri-pubertal) }\end{array}$ & $\begin{array}{c}\text { US, } \\
\text { BCERP cohort } \\
(645)\end{array}$ & $6-8$ years old & $\begin{array}{c}\text { CS or C (7-year } \\
\text { follow-up); annual } \\
\text { pubertal assessment }\end{array}$ & $\begin{array}{c}\text { YES } \\
\text { (DDE and PBDE of } \\
\text { peri-pubertal, late)/ } \\
\text { NO (PCBs) }\end{array}$ & $\begin{array}{l}\text { Higher peri-pubertal DDE } \\
\text { and PBDE exposure was } \\
\text { associated with later onset } \\
\text { of puberty (attenuated } \\
\text { effects of PCBs after BMI } \\
\text { adjustment) }\end{array}$ & Windham, 2015 \\
\hline DDT (serum) & $\begin{array}{l}\text { Kazakhstan } \\
\text { (524) }\end{array}$ & 10-17 years old & $\begin{array}{c}\text { CS; assessed Tanner } \\
\text { stage }\end{array}$ & YES (late) & $\begin{array}{l}\text { Higher levels of DDT were } \\
\text { associated with delayed } \\
\text { pubertal development }\end{array}$ & Bapayeva, 2016 \\
\hline PBDE (serum) & $\begin{array}{c}\text { Italy } \\
\text { (37 with } \mathrm{PP}+56 \text { with } \\
\mathrm{PT}+31 \text { controls) }\end{array}$ & $5-8$ years old & CC & YES (early) & $\begin{array}{l}\text { Higher PBDE levels in girls } \\
\text { with PT than those of } \\
\text { controls }\end{array}$ & Deodati, 2016 $6^{92)}$ \\
\hline $\begin{array}{l}\text { DDT/DDE } \\
\text { (maternal serum) }\end{array}$ & $\begin{array}{c}\text { UK } \\
\text { (218 with } \\
\text { menarche }<11.5 \text { yrs } \\
+230 \text { controls })\end{array}$ & 8-13 years old & $\begin{array}{l}\text { Cor CC (nested); } \\
\text { assessed age at } \\
\text { menarche by } \\
\text { questionnaire } \\
\text { (annually from } \\
\text { ages 8-17) }\end{array}$ & NO & $\begin{array}{l}\text { Prenatal DDT exposure } \\
\text { was not associated with } \\
\text { timing of menarche }\end{array}$ & Namulanda, $2016^{78)}$ \\
\hline $\begin{array}{l}\text { PBDE (maternal } \\
\text { serum, child } \\
\text { serum at } \\
\text { age } 9 \text { years) }\end{array}$ & $\begin{array}{c}\text { US, } \\
\text { CHAMACOS cohort } \\
(314)\end{array}$ & 9-13 years old & $\begin{array}{c}\text { C (followed every } \\
9 \text { months between } \\
\text { 9-13 years of } \\
\text { age); assessed } \\
\text { Tanner stage by } \\
\text { examination }\end{array}$ & $\begin{array}{l}\text { YES (prenatal, late)/ } \\
\text { NO (childhood) }\end{array}$ & $\begin{array}{l}\text { Prenatal PBDE exposure } \\
\text { was associated with } \\
\text { later menarche, while } \\
\text { childhood PBDE levels } \\
\text { were not associated with } \\
\text { pubertal timing }\end{array}$ & Harley, 2017 $7^{93)}$ \\
\hline 3-PBA (urine) & China (305) & $9-15$ years old & $\begin{array}{l}\text { CS; Self-reported } \\
\text { pubertal staging } \\
\text { and menarche } \\
\text { status }\end{array}$ & YES (late) & $\begin{array}{c}\text { Negative association } \\
\text { between urinary } \\
\text { 3-PBA with pubertal } \\
\text { development (breast/ } \\
\text { pubic hair stage, and } \\
\text { menarche) }\end{array}$ & Ye, 2017 ${ }^{81)}$ \\
\hline
\end{tabular}

BCERP, the Breast Cancer and the Environment Research Program; BMI, body mass index; C, cohort study; CC, case-control study; CHAMACOS, the Center for the Health Assessment of Mothers and Children of Salinas; CS, cross-sectional study; DDE, dichlorodiphenyl dichloroethane; DDT, dichlorodiphenyl trichloroethane; NHANES, The National Health and Nutrition Examination Survey; PBB, polybrominated biphenyl; PBDE, polybrominated diphenyl ether; PCBs, polychlorinated biphenyl; PCDD, polychlorinated dibenzodioxins; PCDF, polychlorinated dibenzofurans; PP, precocious puberty; PT, premature thelarche; TCDD, tetrachlorodibenzo-p-dioxin; UK, United Kingdom; US, United States; 3-PBA, 3-phenoxybenzoic acid. 
prenatally was associated with early onset of puberty ${ }^{70)}$ or no relation to puberty, ${ }^{78)}$ whereas higher exposure in childhood was related to later onset of puberty. ${ }^{76)}$

Pyrethroids are the most commonly used residential insecticides, having replaced some of the agricultural use of organophosphorus and carbamate insecticides. Pyrethroids are quickly metabolized and eliminated through the kidneys in humans, and their half-life is less than 10 hours. ${ }^{79)}$ The most frequently utilized pyrethroid biomarker is 3-phenoxyboenzoic acid, and it has been reported as weakly androgenic. ${ }^{80)}$ One cross-sectional study ${ }^{81)}$ reported an association between pyrethroids exposure and later onset of puberty in girls.

\section{Dioxins and PCBs}

Dioxins are byproducts of manufacturing processes, including smelting, bleaching of paper pulp, and the manufacturing of herbicides and pesticides. The chemical name for dioxin is 2,3,7,8-tetrachlorodibenzo para dioxin (TCDD). The name "Dioxins" is often used in chemically and structurally similar compounds, such as polychlorinated dibenzodioxins (PCDDs) and polychlorinated dibenzo furans. Dioxins are known to have estrogenic and antiandrogenic activities, and their half-life is 7-11 years in the body. ${ }^{82)}$ In addition, PCBs also constitute a group of these polychlorinated aromatic hydrocarbons and have similar toxic properties with dioxin. PCBs have estrogenic and antiandrogenic effects, ${ }^{83)}$ and the maximum elimination halflife for PCBs is approximately $10-15$ years. ${ }^{84)}$ The few studies on the relevance of dioxins/PCBs to puberty (Table 3$)^{70,72,73,76,85-}$

${ }^{87)}$ have shown inconsistent and limited data. They have shown a positive association with early onset of menarche ${ }^{72)}$ as well as with delayed pubertal development. ${ }^{73,85)}$ Two longitudinal cohort studies have reported different outcomes: one study reported no association between prenatal PCBs exposure and menarcheal age, ${ }^{70)}$ while the other reported a significant correlation between prenatal PCDD/Fs exposure and delayed breast development. ${ }^{87}$ Other prospective studies on childhood TCDD exposure have reported no associations with pubertal development ${ }^{76)}$ or the onset of menarche. ${ }^{86)}$

\section{Polybrominated flame retardants}

Flame retardants refer to a variety of substances that are added to materials to prevent the start and growth of fires. With approximate half-lives of 2-7 days, they are used in many products, such as furniture, mattresses, carpets, and flameretardant textiles. ${ }^{88)}$ Polybrominated flame retardants include compounds such as PBDEs, PBB, and so on. ${ }^{88)}$ Estrogenic and antiandrogenic activities have been reported with exposure to these compounds. ${ }^{89)}$ To date, there have been limited studies on pubertal timing, with inconsistent results that depend on the timing of exposure (Table 3) ${ }^{76,87,90-93)}$ The limited studies have shown positive associations with premature thelarche, ${ }^{92)}$ earlier pubertal development, ${ }^{90)}$ and age at menarche, ${ }^{91)}$ although associations with later onset of puberty ${ }^{76,93)}$ or no association ${ }^{87)}$ have also been reported. Three prospective studies have reported contrasting outcomes in which prenatal PBB/PBDE exposures showed no association ${ }^{87)}$ or associations with both earlier $^{90)}$ and later ${ }^{93)}$ pubertal timing. Another prospective study reported an association between childhood PBDE exposure and later onset of puberty. ${ }^{76)}$

\section{Revised paradigm of EDCs on pubertal timing and future directions}

Parent et al. ${ }^{2)}$ suggested a revised paradigm of EDCs on pubertal timing. Since improvements in public health and nutrition have paralleled a downward trend in pubertal timing and menarche, environmental factors are the predominant determinants in pubertal timing. Classically, environmental factors, including EDCs, might advance pubertal timing via central mechanisms, particularly during the prepubertal period. According to the revised paradigm, ${ }^{2)}$ environmental factors can influence puberty and reproduction through not only central but also peripheral mechanisms, depending on whether they take place early during fetal and neonatal life or late during the prepubertal period. Environmental factors can affect energy availability during the fetal and neonatal period or in infancy and early childhood. They can also act as obesogens and promote early adiposity rebound, leading to changes in metabolic or peripheral signals and increases in adrenal androgen levels, with subsequent early pubertal development. Environmental factors, including EDCs, might affect genetic or epigenetic pathways during critical windows of development. Further investigation is warranted in order to reveal the underlying mechanisms whereby early-life exposure to EDCs affects the HPG-peripheral tissue axis.

\section{Conclusion}

The onset of puberty in girls is occurring earlier, without changes in the timing of completion of puberty. Physiological variability and multiple other factors affect the initiation of puberty. Exposure to a broad mixture of EDCs is ubiquitous, and the shifts in pubertal timing may be mediated by exposures to EDCs at critical developmental windows. EDCs are hormonally active substances that can act via several mechanisms to perturb puberty either peripherally on target organs (adipose tissue or adrenal glands) or centrally via the HPG axis. EDCs can influence pubertal timing through different mechanisms depending on when the exposure occurs during early-life. Evidence for associations between exposures of EDCs and altered pubertal timing makes it reasonable to support the hypothesis that a relationship between EDCs and pubertal timing exists. However, the current data is insufficient and conflicting to provide sufficient evidence for a causal relationship between EDCs exposure and changes in pubertal timing in humans. Further human epidemiologic studies of 
prospective and longitudinal design are needed to determine the combined effect of EDC exposure on puberty and reproduction during critical periods. In addition, the underlying mechanisms whereby early-life exposures to EDCs influence puberty, including epigenetic marks, need to be explored in further studies.

\section{Conflicts of interest}

No potential conflict of interest relevant to this article was reported.

\section{Acknowledgments}

This study was supported by grants from the Basic Science Research Program through the National Research Foundation of Korea funded by the Ministry of Education (2018R1D1A1B07049806).

\section{References}

1. Abreu AP, Kaiser UB. Pubertal development and regulation. Lancet Diabetes Endocrinol 2016;4:254-64.

2. Parent AS, Franssen D, Fudvoye J, Gérard A, Bourguignon JP. Developmental variations in environmental influences including endocrine disruptors on pubertal timing and neuroendocrine control: Revision of human observations and mechanistic insight from rodents. Front Neuroendocrinol 2015;38:12-36.

3. hn JH, Lim SW, Song BS, Seo J, Lee JA, Kim DH, et al. Age at menarche in the Korean female: secular trends and relationship to adulthood body mass index. Ann Pediatr Endocrinol Metab 2013;18:60-4.

4. Cho GJ, Park HT, Shin JH, Hur JY, Kim YT, Kim SH, et al. Age at menarche in a Korean population: secular trends and influencing factors. Eur J Pediatr 2010;169:89-94.

5. Aksglaede L, Sørensen K, Petersen JH, Skakkebaek NE, Juul A. Recent decline in age at breast development: the Copenhagen Puberty Study. Pediatrics 2009;123:e932-9.

6. Zhu J, Kusa TO, Chan YM. Genetics of pubertal timing. Curr Opin Pediatr 2018;30:532-40.

7. Biro FM, Khoury P, Morrison JA. Influence of obesity on timing of puberty. Int J Androl 2006;29:272-7; discussion 286-90.

8. Cheng G, Buyken AE, Shi L, Karaolis-Danckert N, Kroke A, Wudy SA, et al. Beyond overweight: nutrition as an important lifestyle factor influencing timing of puberty. Nutr Rev 2012;70:133-52.

9. Dunger DB, Ahmed ML, Ong KK. Early and late weight gain and the timing of puberty. Mol Cell Endocrinol 2006;254-255:140-5.

10. Gore AC, Chappell VA, Fenton SE, Flaws JA, Nadal A, Prins GS, et al. EDC-2: The Endocrine Society's Second Scientific Statement on Endocrine-Disrupting Chemicals. Endocr Rev 2015;36:E1-E150.
11. Frisch RE, Revelle R. Height and weight at menarche and a hypothesis of critical body weights and adolescent events. Science 1970;169:397-9.

12. Elks CE, Perry JR, Sulem P, Chasman DI, Franceschini N, $\mathrm{He} \mathrm{C}$, et al. Thirty new loci for age at menarche identified by a meta-analysis of genome-wide association studies. Nat Genet 2010;42:1077-85.

13. Perry JR, Day F, Elks CE, Sulem P, Thompson DJ, Ferreira T, et al. Parent-of-origin-specific allelic associations among 106 genomic loci for age at menarche. Nature 2014;514:927.

14. Willemsen RH, Dunger DB. Normal variation in pubertal timing: genetic determinants in relation to growth and adiposity. Endocr Dev 2016;29:17-35.

15. Roth CL, DiVall S. Consequences of early life programing by genetic and environmental influences: a synthesis regarding pubertal Timing. Endocr Dev 2016;29:134-52.

16. Kaplowitz PB, Slora EJ, Wasserman RC, Pedlow SE, Herman-Giddens ME. Earlier onset of puberty in girls: relation to increased body mass index and race. Pediatrics 2001;108:347-53.

17. Shalitin S, Kiess W. Putative Effects of Obesity on Linear Growth and Puberty. Horm Res Paediatr 2017;88:101-10.

18. Lomniczi A, Loche A, Castellano JM, Ronnekleiv OK, Bosch M, Kaidar G, et al. Epigenetic control of female puberty. Nat Neurosci 2013;16:281-9.

19. Vazquez MJ, Toro CA, Castellano JM, Ruiz-Pino F, Roa J, Beiroa D, et al. SIRT1 mediates obesity- and nutrient-dependent perturbation of pubertal timing by epigenetically controlling Kiss 1 expression. Nat Commun 2018;9:4194.

20. Parent AS, Franssen D, Fudvoye J, Pinson A, Bourguignon JP. Current changes in pubertal timing: revised vision in relation with environmental factors including endocrine disruptors. Endocr Dev 2016;29:174-84.

21. Parent AS, Teilmann G, Juul A, Skakkebaek NE, Toppari J, Bourguignon JP. The timing of normal puberty and the age limits of sexual precocity: variations around the world, secular trends, and changes after migration. Endocr Rev 2003;24:668-93.

22. Euling SY, Selevan SG, Pescovitz OH, Skakkebaek NE. Role of environmental factors in the timing of puberty. Pediatrics 2008;121 Suppl 3:S167-71. pii: E5. https://doi. org/10.3390/toxics7010005.

23. Combarnous Y, Nguyen TMD. Comparative overview of the mechanisms of action of hormones and endocrine disruptor compounds. Toxics 2019;7.

24. Bourguignon JP, Juul A, Franssen D, Fudvoye J, Pinson A, Parent AS. Contribution of the endocrine perspective in the evaluation of endocrine disrupting chemical effects: the case study of pubertal timing. Horm Res Paediatr 2016;86:221-32.

25. Mouritsen A, Aksglaede L, Sørensen K, Mogensen SS, Leffers H, Main KM, et al. Hypothesis: exposure to endocrine-disrupting chemicals may interfere with timing of puberty. Int J Androl 2010;33:346-59. 
26. Greenspan LC, Lee MM. Endocrine disrupters and pubertal timing. Curr Opin Endocrinol Diabetes Obes. 2018;25(1):49-54.

27. Völkel W, Colnot T, Csanády GA, Filser JG, Dekant W. Metabolism and kinetics of bisphenol a in humans at low doses following oral administration. Chem Res Toxicol 2002;15:1281-7.

28. Wetherill YB, Akingbemi BT, Kanno J, McLachlan JA, Nadal A, Sonnenschein C, et al. In vitro molecular mechanisms of bisphenol A action. Reprod Toxicol 2007;24:178-98.

29. Han EJ, Yim OK, Chung J, Baek SY, Kim Y. The study of relationship between the concentrations of Bisphenol A and DEHP in human plasma and precocious puberty. Anal Sci Technol 2008;21:375-82.

30. Wolff MS, Britton JA, Boguski L, Hochman S, Maloney N, Serra N, et al. Environmental exposures and puberty in inner-city girls. Environ Res 2008;107:393-400.

31. Lee SW, Lee WJ, Chae HW, Lee EB, Kim JH, Kim DH, et al. Determination of serum Di-(2-ethylhexyl) phthalate and bisphenol A level in children with idiopathic central precocious puberty. J Korean Soc Pediatr Endocrinol 2009; 14:154-62.

32. Qiao L, Zheng L, Cai D. Study on the levels of the bisphenol A, octylphenol, 4-nonylphenol in serum of precocious girls. Wei Sheng Yan Jiu 2010;39:9-12.

33. Wolff MS, Teitelbaum SL, Pinney SM, Windham G, Liao L, Biro F, et al. Investigation of relationships between urinary biomarkers of phytoestrogens, phthalates, and phenols and pubertal stages in girls. Environ Health Perspect 2010;118:1039-46.

34. Buttke DE, Sircar K, Martin C. Exposures to endocrinedisrupting chemicals and age of menarche in adolescent girls in NHANES (2003-2008). Environ Health Perspect 2012;120:1613-8

35. Frederiksen H, Aksglaede L, Sorensen K, Nielsen O, Main KM, Skakkebaek NE, et al. Bisphenol A and other phenols in urine from Danish children and adolescents analyzed by isotope diluted TurboFlow-LC-MS/MS. Int J Hyg Environ Health 2013;216:710-20.

36. Yum T, Lee S, Kim Y. Association between precocious puberty and some endocrine disruptors in human plasma. J Environ Sci Health A Tox Hazard Subst Environ Eng 2013;48:912-7.

37. Durmaz E, Aşçı A, Erkekoğlu P, Akçurin S, Gümüşel BK, Bircan I. Urinary bisphenol a levels in girls with idiopathic central precocious puberty. J Clin Res Pediatr Endocrinol 2014;6:16-21.

38. Lee SH, Kang SM, Choi MH, Lee J, Park MJ, Kim SH, et al. Changes in steroid metabolism among girls with precocious puberty may not be associated with urinary levels of bisphenol A. Reprod Toxicol 2014;44:1-6.

39. Chen LH, Shi JR, Fang YL, Liang L, Chen WQ, Chen XZ. Serum bisphenol A concentration and premature thelarche in female infants aged 4-month to 2-year. Indian J Pediatr 2015;82:221-4.

40. McGuinn LA, Ghazarian AA, Joseph Su L, Ellison
GL. Urinary bisphenol A and age at menarche among adolescent girls: evidence from NHANES 2003-2010. Environ Res 2015;136:381-6.

41. Wolff MS, Teitelbaum SL, McGovern K, Pinney SM, Windham GC, Galvez M, et al. Environmental phenols and pubertal development in girls. Environ Int 2015;84:174-80.

42. Buluş AD, Așci A, Erkekoglu P, Balci A, Andiran N, KoçerGümüssel B. The evaluation of possible role of endocrine disruptors in central and peripheral precocious puberty. Toxicol Mech Methods 2016;26:493-500.

43. Özgen İT, Torun E, Bayraktar-Tanyeri B, Durmaz E, Kılıç E, Cesur Y. The relation of urinary bisphenol A with kisspeptin in girls diagnosed with central precocious puberty and premature thelarche. J Pediatr Endocrinol Metab 2016;29:337-41.

44. Supornsilchai V, Jantarat C, Nosoognoen W, Pornkunwilai $\mathrm{S}$, Wacharasindhu S, Soder O. Increased levels of bisphenol A (BPA) in Thai girls with precocious puberty. J Pediatr Endocrinol Metab 2016;29:1233-9.

45. Kasper-Sonnenberg M, Wittsiepe J, Wald K, Koch HM, Wilhelm M. Pre-pubertal exposure with phthalates and bisphenol A and pubertal development. PLoS One 2017;12:e0187922.

46. Miao M, Wang Z, Liu X, Liang H, Zhou Z, Tan H, et al. Urinary bisphenol A and pubertal development in Chinese school-aged girls: a cross-sectional study. Environ Health 2017;16:80

47. Wolff MS, Pajak A, Pinney SM, Windham GC, Galvez M, Rybak M, et al. Associations of urinary phthalate and phenol biomarkers with menarche in a multiethnic cohort of young girls. Reprod Toxicol 2017;67:56-64.

48. Watkins DJ, Sánchez BN, Téllez-Rojo MM, Lee JM, Mercado-García A, Blank-Goldenberg C, et al. Phthalate and bisphenol A exposure during in utero windows of susceptibility in relation to reproductive hormones and pubertal development in girls. Environ Res 2017;159:14351.

49. Berger K, Eskenazi B, Kogut K, Parra K, Lustig RH, Greenspan LC, et al. Association of prenatal urinary concentrations of phthalates and bisphenol A and pubertal timing in boys and girls. Environ Health Perspect 2018;126:97004

50. Chen Y, Wang Y, Ding G, Tian Y, Zhou Z, Wang X, et al. Association between bisphenol a exposure and idiopathic central precocious puberty (ICPP) among school-aged girls in Shanghai, China. Environ Int 2018;115:410-6.

51. Durmaz E, Asci A, Erkekoglu P, Balcı A, Bircan I, KoçerGumusel B. Urinary bisphenol A levels in Turkish girls with premature thelarche. Hum Exp Toxicol 2018;37:1007-16.

52. Leonardi A, Cofini M, Rigante D, Lucchetti L, Cipolla C, Penta L, et al. The effect of bisphenol A on puberty: a critical review of the medical literature. Int J Environ Res Public Health 2017;14.

53. Benjamin S, Masai E, Kamimura N, Takahashi K, Anderson RC, Faisal PA. Phthalates impact human health: epidemiological evidences and plausible mechanism of 
action. J Hazard Mater 2017;340:360-83.

54. Colón I, Caro D, Bourdony CJ, Rosario O. Identification of phthalate esters in the serum of young Puerto Rican girls with premature breast development. Environ Health Perspect 2000;108:895-900.

55. Qiao L, Zheng L, Cai D. Study on the di-n-butyl phthalate and di-2-ethylhexyl phthalate level of girl serum related with precocious puberty in Shanghai. Wei Sheng Yan Jiu 2007;36:93-5.

56. Chou YY, Huang PC, Lee CC, Wu MH, Lin SJ. Phthalate exposure in girls during early puberty. J Pediatr Endocrinol Metab 2009;22:69-77.

57. Frederiksen H, Sørensen K, Mouritsen A, Aksglaede L, Hagen CP, Petersen JH, et al. High urinary phthalate concentration associated with delayed pubarche in girls. Int J Androl 2012;35:216-26.

58. Chen CY, Chou YY, Wu YM, Lin CC, Lin SJ, Lee CC. Phthalates may promote female puberty by increasing kisspeptin activity. Hum Reprod 2013;28:2765-73.

59. Mouritsen A, Frederiksen H, Sørensen K, Aksglaede L, Hagen C, Skakkebaek NE, et al. Urinary phthalates from 168 girls and boys measured twice a year during a 5-year period: associations with adrenal androgen levels and puberty. J Clin Endocrinol Metab 2013;98:3755-64.

60. Wolff MS, Teitelbaum SL, McGovern K, Windham GC, Pinney SM, Galvez M, et al. Phthalate exposure and pubertal development in a longitudinal study of US girls. Hum Reprod 2014;29:1558-66.

61. Zhang Y, Cao Y, Shi H, Jiang X, Zhao Y, Fang X, et al. Could exposure to phthalates speed up or delay pubertal onset and development? A 1.5-year follow-up of a school-based population. Environ Int 2015;83:41-9.

62. Srilanchakon K, Thadsri T, Jantarat C, Thengyai S, Nosoognoen W, Supornsilchai V. Higher phthalate concentrations are associated with precocious puberty in normal weight Thai girls. J Pediatr Endocrinol Metab 2017;30:1293-8.

63. Binder AM, Corvalan C, Calafat AM, Ye X, Mericq V, Pereira A, et al. Childhood and adolescent phenol and phthalate exposure and the age of menarche in Latina girls. Environ Health 2018;17:32.

64. Durmaz E, Erkekoglu P, Asci A, Akçurin S, Bircan İ, KocerGumusel B. Urinary phthalate metabolite concentrations in girls with premature thelarche. Environ Toxicol Pharmacol 2018;59:172-81.

65. Hashemipour M, Kelishadi R, Amin MM, Ebrahim K. Is there any association between phthalate exposure and precocious puberty in girls? Environ Sci Pollut Res Int 2018;25:13589-96.

66. Mnif W, Hassine AI, Bouaziz A, Bartegi A, Thomas O, Roig B. Effect of endocrine disruptor pesticides: a review. Int J Environ Res Public Health 2011;8:2265-303.

67. Crellin NK, Rodway MR, Swan CL, Gillio-Meina C, Chedrese PJ. Dichlorodiphenyldichloroethylene potentiates the effect of protein kinase A pathway activators on progesterone synthesis in cultured porcine granulosa cells.
Biol Reprod 1999;61:1099-103.

68. Tsai WT. Current status and regulatory aspects of pesticides considered to be persistent organic pollutants (POPs) in Taiwan. Int J Environ Res Public Health 2010;7:3615-27.

69. Turusov V, Rakitsky V, Tomatis L. Dichlorodiphenyltrichloroethane (DDT): ubiquity, persistence, and risks. Environ Health Perspect 2002;110:125-8.

70. Vasiliu O, Muttineni J, Karmaus W. In utero exposure to organochlorines and age at menarche. Hum Reprod 2004;19:1506-12.

71. Ouyang F, Perry MJ, Venners SA, Chen C, Wang B, Yang F, et al. Serum DDT, age at menarche, and abnormal menstrual cycle length. Occup Environ Med 2005;62:878-84.

72. Denham M, Schell LM, Deane G, Gallo MV, Ravenscroft J, DeCaprio AP, et al. Relationship of lead, mercury, mirex, di chlorodiphenyldichloroethylene, hexachlorobenzene, and polychlorinated biphenyls to timing of menarche among Akwesasne Mohawk girls. Pediatrics 2005;115:e127-34.

73. Den Hond E, Dhooge W, Bruckers L, Schoeters G, Nelen $\mathrm{V}$, van de Mieroop E, et al. Internal exposure to pollutants and sexual maturation in Flemish adolescents. J Expo Sci Environ Epidemiol 2011;21:224-33.

74. Deng F, Tao FB, Liu DY, Xu YY, Hao JH, Sun Y, et al. Effects of growth environments and two environmental endocrine disruptors on children with idiopathic precocious puberty. Eur J Endocrinol 2012;166:803-9.

75. Ozen S, Darcan S, Bayindir P, Karasulu E, Simsek DG, Gurler T. Effects of pesticides used in agriculture on the development of precocious puberty. Environ Monit Assess 2012;184:4223-32.

76. Windham GC, Pinney SM, Voss RW, Sjödin A, Biro FM, Greenspan LC, et al. Brominated flame retardants and other persistent organohalogenated compounds in relation to timing of puberty in a longitudinal study of girls. Environ Health Perspect 2015;123:1046-52.

77. Bapayeva G, Issayeva R, Zhumadilova A, Nurkasimova R, Kulbayeva S, Tleuzhan R. Organochlorine pesticides and female puberty in South Kazakhstan. Reprod Toxicol 2016;65:67-75.

78. Namulanda G, Maisonet M, Taylor E, Flanders WD, Olson $\mathrm{D}$, Sjodin A, et al. In utero exposure to organochlorine pesticides and early menarche in the Avon Longitudinal Study of Parents and Children. Environ Int 2016;94:467-72.

79. Morgan MK, MacMillan DK, Zehr D, Sobus JR. Pyrethroid insecticides and their environmental degradates in repeated duplicate-diet solid food samples of 50 adults. J Expo Sci Environ Epidemiol 2018;28:40-5.

80. Burns CJ, Pastoor TP. Pyrethroid epidemiology: a qualitybased review. Crit Rev Toxicol 2018;48:297-311.

81. Ye X, Pan W, Zhao Y, Zhao S, Zhu Y, Liu W, et al. Association of pyrethroids exposure with onset of puberty in Chinese girls. Environ Pollut 2017;227:606-12.

82. Schecter A, Birnbaum L, Ryan JJ, Constable JD. Dioxins: an overview. Environ Res 2006;101:419-28.

83. Carpenter DO. Polychlorinated biphenyls (PCBs): routes of exposure and effects on human health. Rev Environ Health 
2006;21:1-23.

84. Ritter R, Scheringer M, MacLeod M, Moeckel C, Jones KC, Hungerbühler K. Intrinsic human elimination half-lives of polychlorinated biphenyls derived from the temporal evolution of cross-sectional biomonitoring data from the United Kingdom. Environ Health Perspect 2011;119:22531

85. Den Hond E, Roels HA, Hoppenbrouwers K, Nawrot T, Thijs L, Vandermeulen C, et al. Sexual maturation in relation to polychlorinated aromatic hydrocarbons: Sharpe and Skakkebaek's hypothesis revisited. Environ Health Perspect 2002;110:771-6.

86. Warner M, Samuels S, Mocarelli P, Gerthoux PM, Needham L, Patterson DG Jr, et al. Serum dioxin concentrations and age at menarche. Environ Health Perspect 2004;112:128992.

87. Leijs MM, Koppe JG, Olie K, van Aalderen WM, Voogt Pd, Vulsma T, et al. Delayed initiation of breast development in girls with higher prenatal dioxin exposure; a longitudinal cohort study. Chemosphere 2008;73:999-1004.

88. Sjödin A, Patterson DG Jr, Bergman A. A review on human exposure to brominated flame retardants--particularly polybrominated diphenyl ethers. Environ Int 2003;29:82939.

89. Yang W, Mu Y, Giesy JP, Zhang A, Yu H. Anti-androgen activity of polybrominated diphenyl ethers determined by comparative molecular similarity indices and molecular docking. Chemosphere 2009;75:1159-64.

90. Blanck HM, Marcus M, Tolbert PE, Rubin C, Henderson AK, Hertzberg VS, et al. Age at menarche and tanner stage in girls exposed in utero and postnatally to polybrominated biphenyl. Epidemiology 2000;11:641-7.

91. Chen A, Chung E, DeFranco EA, Pinney SM, Dietrich KN. Serum PBDEs and age at menarche in adolescent girls: analysis of the National Health and Nutrition Examination Survey 2003-2004. Environ Res 2011;111:831-7.

92. Deodati A, Sallemi A, Maranghi F, Germani D, Puglianiello A, Baldari F, et al. Serum levels of polybrominated diphenyl ethers in girls with premature thelarche. Horm Res Paediatr 2016;86:233-9.

93. Harley KG, Rauch SA, Chevrier J, Kogut K, Parra KL, Trujillo C, et al. Association of prenatal and childhood PBDE exposure with timing of puberty in boys and girls. Environ Int 2017;100:132-8. 